\title{
Extending a geographic lens towards climate justice, part 1: climate change characterization and impacts
}

\author{
Authors: \\ Morey Burnham, Department of Environment and Society, Utah State University \\ Claudia Radel,* Department of Environment and Society, Utah State University \\ Zhao Ma, Department of Environment and Society, Utah State University \\ Ann Laudati, School of Geographical Sciences, University of Bristol \\ *Corresponding author \\ 5215 Old Main Hill, Logan, UT 84322-5215; tel. 435-797-0516; email claudia.radel@usu.edu

\section{Citation:} \\ Burnham, M., Radel, C., Ma, Z., \& Laudati, A. (2013). Extending a geographic lens towards \\ climate justice, part 1: climate change characterization and impacts. Geography Compass, 7(3), \\ 239-248.
}

\begin{abstract}
:
There has been a recent increase of interest within the academic literature on the justice issues posed by climate change and the human responses to its present and forecasted effects. This literature is partially shaped by debates from environmental justice scholarship, but also has roots in various subfields of geography. In two parts (here and in a subsequent article), we review and synthesize the recent literature by asking what climate justice concerns have been identified within three related realms: 1 ) the characterization of climate change itself and the assignment of responsibility for that change; 2 ) the differential or uneven impacts of climate change; and 3 ) the actions taken to address the problems associated with climate change, including mitigation and adaptation. Here, in Part 1, we provide a basic outline of justice concepts; we address the characterization of climate change and the associated discursive framings; and we discuss the uneven impacts of climate change with a focus on the conceptualization of vulnerability. We suggest that the field of geography has much to offer to the debate on climate justice because of its unique understandings of the human-environment relationship based on a longstanding engagement with the spatiality and scale of environmental change, the corresponding human impacts, and the conceptual inseparability of nature and society. We identify, across Part 1 and Part 2, the need for a more comprehensive theory of justice to inform climate justice considerations-one that pays more attention to linked procedural, recognition, and scalar concerns.
\end{abstract}




\section{Introduction}

Climate justice has emerged as both a field of political activism and a realm of scholarly debate and research. Several of geography's established traditions pull geographers into the climate justice debate and into empirical research of direct relevance to the debate. The most important of these traditions are: conceptualizing vulnerability in the context of environmental hazards, understanding the spatial distribution of environmental burdens, and exploring aspects of structure, agency, and adaptation in smallholder agricultural systems of the Global South, particularly in the context of conservation and/or development projects. Moreover, the examination of climate justice dilemmas is fundamentally geographic as they largely arise from the geographic mismatch between climate change causes and consequences across the surface of the planet.

In this two-part review, we outline the broad contours of the climate justice debate, paying particular attention to justice questions at various analytic scales with an eye towards cross-scalar issues. We pay attention to geographers' contributions to-date, the topical areas into which geographers are moving, and the contributions outside of geography that we consider most important to a geography of climate justice. Here in Part 1, we first briefly summarize the types of justice central to the debate for readers unfamiliar with justice theorization. We then structure our literature review by the first two of three core categories of justice dilemmas: the characterization of climate change and climate change impacts. In Part 2, we review the third core category of justice dilemmas: societal responses to climate change, or climate action. Finally, we return to consider justice itself, in the context of climate change.

We argue, across Part 1 and Part 2, that we need to develop a more comprehensive theory of justice to inform climate justice considerations-one that pays more attention to linked procedural, recognition, and scalar concerns. Within global climate policy, climate justice has been conceptualized as a matter among state actors, resulting in various contradictory justice outcomes-an argument we develop in Part 2 of our review. Questions of justice at the international scale have become cemented largely into a "developed nation-developing nation" binary (Kythreotis 2011), with small island states presenting a discursively important (Farbotko and Lazrus 2012) third position. Although our scalar argument relates in particular to climate action, it relates as well to the characterization of climate change and the analysis and conceptualization of vulnerabilities to climate change impacts. For example, the available state subject positions have acted to veil the differences among actors at sub-national scales with regards to climate change impacts.

\section{Brief Review of the Types of Justice}

Within the literature on climate justice two types of justice emerge as primary: distributive and procedural, or, more broadly, outcome and process (Ikeme 2003; Paavola and Adger 2006). Distributive justice posits that the benefits and burdens of climate change will be differentially distributed across space and time, requiring a redistributive response. Procedural justice argues that fair distribution of the benefits and burdens of climate change (and of society's responses, as discussed in Part 2) can only be achieved if all affected parties are involved in an equitable decision-making process (Ikeme 2003). Rooted in Rawls' (1971) assertion that fairness in the bargaining process leads to a fair result, procedural justice highlights the importance of voice and participation in institutional decision-making. Fraser 
(1997) discusses a third type of justice - that of recognition, which is overlapping yet also distinct from procedural justice. Recognition relates to social and cultural difference and has been tied to contemporary identity politics. In essence, "recognition justice" argues for the existence rights of different cultural and social groups, with respect given to these differences, in the face of climate change. Recognition, as also distinguished by Schlosberg (2007) and applied to environmental justice within geography by Walker (2010), only recently has begun to be examined by climate justice scholars. As Marino and Ribot (2012) point out, this type of justice considers the damage inflicted by both lack of recognition and misrecognition of different social groups within the discourses of climate change.

\section{Justice and the Characterization of Climate Change}

The way government, activists, policy makers, and academics frame environmental issues (and relevant solutions) is important to understanding how environmental issues are understood and acted upon. Taylor (2000, p. 511) defines issue framing as the way that "individuals and groups identify, interpret, and express social and political grievances." Framing shapes how we determine the causal mechanisms of environmental problems, how we understand who is to blame and who will suffer as a result, and what we see as the appropriate actions that need to be taken. Discourses or narratives surrounding climate change are central to this framing, and not only set the agenda and corresponding actions, but also indicate how the effects of those actions are understood as (in)appropriate and/or (un)just. This section examines several frames various scholars have identified as driving climate change discourse and associated justice concerns. Geographer Liverman's work (2009) has been especially important in this area.

One of the most important discursive climate change frames has been that of "dangerous climate change," and the fixation on a $2^{\circ}$ celsius increase as the danger threshold (Liverman 2009). Originating within the field of climate science, the "dangerous climate change" concept has been used by the United Nations Framework Convention on Climate Change (UNFCCC) to signify the level at which greenhouse gas (GHG) concentrations need to be stabilized in order to avoid "dangerous anthropogenic interference with the atmosphere" and subsequent negative impacts on human and biophysical systems. The concept itself is difficult to measure and operationalize and has been daunting for the public to comprehend (Hulme 2008; Liverman 2009; Peet et al. 2011). Moreover, achieving climate justice through the use of the "dangerous climate change" concept is problematic for three reasons. First, as Liverman (2009) notes, "dangerous" is a highly subjective and value-laden term. Thus, the distributive question of dangerous for whom arises. What constitutes danger for one community is not necessarily dangerous for another, and how danger is defined is linked to scale and perception of risk. A post-industrial society may not perceive current climate patterns as dangerous, but may regard future projected conditions as potentially harmful. Conversely, a small island nation with low adaptive capacity is more likely to perceive current climatic conditions as an immediate threat. A second question linked to procedural justice concerns for advocates of climate change justice is who is then enabled and empowered to define the dangerous levels of atmospheric GHG concentrations and the resulting warming (Desai et al. 2004; Liverman 2009). Lastly, the "dangerous climate change" frame has focused attention on the biophysical impacts, 
with resultant inadequate attention to humans rights (Liverman 2009) and justice concerns such as recognition.

A second framing with implications for justice is that of "common but differentiated responsibility" (Liverman 2009). How responsibility for climate change is framed directly shapes the allocation of financial and action obligations or expectations by country, countryblock, or region. Thus, questions of who and what are contributors to GHG emissions deeply matter as they affect the ability of countries to pursue development goals and achieve or maintain certain standards of well-being for their citizens (Roberts 2009). This is particularly significant to current discussions regarding the treatment of historical versus current, consumption-based versus production-based, and subsistence versus luxury emissions. In an effort to change the current framing of climate change responsibility, Roberts and Parks (2009) draw upon the combined concepts of ecological debt and ecologically unequal exchange to highlight how contemporary unequal trade relations between the Global North and South raise questions of responsibility central to climate justice concerns. Ultimately, they argue, the increased participation in international trade by developing countries increases their emissions while allowing developed countries to lower theirs. As many of the products produced in the Global South are exported to feed the lifestyles of the Global North, the environmental burdens associated with the extraction and export of these products are subsequently displaced from the North to the South. The result of this burden displacement is an accumulated ecological debt, owed by countries in the Global North to countries in the Global South. Such a reframing raises important questions over who is responsible for those emissions, and ultimately, who is responsible for cutting them. Another proffered alternative framework is that of Greenhouse Development Rights (Baer et al. 2008), which focuses on the rights of the poor to well-being in a "climate constrained world." It is important to note here that the current frame, as well as the proffered alternative, veils differences within countries by aggregating at the country level and setting the state as the actor.

Although weakly represented in the literature, we draw attention to a third climate change narrative which frames climate change as the "natural" outcome of human population growth, improvements in consumption, and the development of a fossil-fuel based economy. Ecofeminist philosopher Sturgeon (2007) argues that the naturalization of certain processes of climate change holds serious implications for justice by maintaining existing social systems that many deem unjust. Naturalization narratives may in fact reinforce and reproduce the uneven power relations embedded in certain forms of state intervention and the development apparatus that are the very cause of environmental problems. One illustrative example is the climate change discourse of winners and losers. Winners are defined by their improved economic conditions and quality-of-life opportunities resulting from climate change and losers are defined by loss of livelihood, increased vulnerability, and other negative effects suffered. According to this narrative, winners and losers are conceived as products of either natural or inevitable processes that are the consequence of ecological or economic positioning, or unequal social and political conditions. O'Brien and Leichenko (2003) note that, like the term "dangerous climate change," how winners and losers are defined is highly subjective and dependent on scale and temporal considerations. How and who defines wins and losses is crucial to justice outcomes, and attempts to do so need to come from multiple scales and perspectives to ensure just outcomes. The metrics used and the way they are aggregated also 
have important implications for climate justice. Funneling groups of people into rigid and naturalized categories of winners and losers denies the role of local actors as active agents in negotiating and defining climate action. A frame that highlights climate change as a "natural" outcome of human population growth also simultaneously legitimizes calls to withhold critical resources from affected "loser" populations via a neo-malthusianesque system of triage.

\section{Justice and Climate Change Impacts}

The distribution of current and future climate change impacts is one of the most acknowledged climate justice dilemmas. Differential impacts across generations raise justice concerns as the generations responsible for GHG emissions will be less affected than future generations (Okereke 2006). The differential impacts across space and social structures, in contrast, are typically discussed in terms of vulnerability, a concept geographers have played a large part in establishing through research in the social dimensions of natural and environmental hazards (e.g., Blaikie et al. 1994). In this section we briefly discuss the competing ways vulnerability has been defined and then highlight in more detail several themes within the literature that focus on questions of vulnerability and the differential distribution of climate change impacts. How vulnerability is defined and measured is key to climate justice as it subsequently affects the types of actions taken to respond to climate change and determines who will benefit and how from these actions.

The concept of vulnerability has both scientific and political dimensions (Klein and Mohner 2011). It is both a category of analysis and a category of practice. As a category of analysis it is used as a way to capture the differential distribution of climate change impacts; while as a category of practice, it structures adaptation funding decisions by various global institutions. Arguably, there is an abundance of both conceptual and methodological confusion and murkiness associated with vulnerability. A multitude of definitions and assessment approaches exist, and little consensus has been reached across the multiple camps deploying the term about what it means or how it should be measured. An exhaustive review of the competing definitions of vulnerability is beyond the scope of this paper (see Adger 2006; Eakin and Luehrs 2006 for reviews). For our purposes, we broadly conceptualize three general types of vulnerability based on where researchers or practitioners locate the risk inherent in climatesociety interactions. O'Brien et al. (2007) have usefully distinguished the first two types as outcome and contextual vulnerability. Outcome vulnerability understands vulnerability to be the projected impacts of anthropogenic climate change on biophysical and social systems and is often measured in terms such as sea level rise and subsequent inundation of low-lying coastal lands or the economic effects of reductions in crop production. In contrast, contextual vulnerability asserts that damages incurred from climate change are a product of "conditions on the ground" (e.g., unequal resource access, poverty, lack of infrastructure), in which political, economic, social, and institutional structures and changes interact with climate change and variability causing differential capacities to respond. Here, vulnerability is often measured in terms such as access to resources (McDowell and Hess 2012), entitlements (Ribot 2010), coping strategies (Eriksen et al. 2005), and socioeconomic inequality. The final vulnerability type merges the first two in a metric that describes a system's sensitivity to harm from exposure to climate change based on environmental and social variables, as well as a lack of adaptive capacity (Adger 2006). 
The connection between vulnerability and climate justice is most apparent when taking into account the mismatch between those who are responsible for the changing climate and those who are most vulnerable to its impacts. When developing justice claims, Walker (2010) suggests that both patterns of responsibility (i.e., who produced the hazard) and patterns of outcome (i.e., who is impacted) need to be taken into account. According to the polluter-paysprinciple, those who created the problem by emitting GHGs are obligated to take mitigation actions and provide resources for adaptation to those who bear a disproportionate share of the impacts. Some justice scholars consider it essential that these payments be framed as necessary compensation rather than as charity or aid (e.g., Roberts 2009).

However, how we define and operationalize vulnerability is key to some of the less readily apparent justice issues in climate change impacts. Increasingly geographers have recognized that underlying social, political, and ecological inequalities, rather than merely exposure to a changing climate, are central to understanding how climate change impacts are produced. Both situational and structural drivers of vulnerability are important to determining how people and places will be affected differently by climate change (Dow et al. 2006;

Kasperson and Kasperson 2001; Mearns and Norton 2010; Ribot 2010), as well as their adaptive capacity (Adger 2006; Handmer et al. 1999; Heltberg et al. 2009). This literature suggests that vulnerability is distributed differentially not only across communities, nations, and regions, but also across races, ethnicities, ages, classes, income levels, occupations, and genders (Roberts 2009; Terry 2009; Walker 2010). Senior citizens and the disabled, for example, may be more vulnerable to a changing climate, as can be seen from the high death rates in these population segments in the French heat wave of 2003 (Leichenko and O'Brien 2008). Furthermore, Ribot (2010) suggests that in order to achieve equity in climate outcomes, vulnerability analyses must be pointedly pro-poor in conception and outlook so that biases against the marginalized and poor can be avoided in policy solutions.

The gendered aspect of uneven climate exposure is occupying growing prominence in the literature. Eriksen et al. (2005), for example, argue that women are exposed to a greater share of climate change impacts as the dominant worker in household agriculture in the Global South. Research has demonstrated the existence of gender-specific barriers that limit women's capacities to adapt to and cope with climate change (Terry 2009). And work by geographers like Sultana (2010) on gender and water highlights these differential burdens and barriers. As a caution, Arora-Jonsson (2011) argues that the common yet empirically unsupported discourse which posits women-as an undifferentiated category-as more vulnerable to climate change actually runs the risk of making individual women's specific vulnerabilities invisible. By uncritically assuming the vulnerability of a social category, discourses such as this ignore more important issues of how power permeates social relations and decision-making processes, reproduce inequalities across scales, attribute fault to the individual, and ignore how inequalities are structurally produced (Arora-Jonsson 2011).

\section{Further Reflections on Justice, Race, and Analytical Scale}

In Part 1 of our review, we present a synthesis of the recent literature on climate justice as related by and relevant to geographic scholarship in two areas - the characterization of climate change and climate change impacts. Key themes that emerged include the framings of climate change discourses, mismatches in the responsibilities for and burdens of climate 
change, and the social-spatial production of risk and vulnerability. Within these themes, the field of geography has much to offer to the debate on climate justice because of its unique understanding of the human-environment relationship based on a longstanding engagement with the spatiality and scale of environmental change and the corresponding human impacts. Importantly, geography has also long posited the conceptual inseparability of nature and society, as we understand environmental changes to be socially constructed and the impacts of those changes to reflect the interactions of biophysical processes with social processes. While our review is not a comprehensive review of all climate justice scholarship, its directed approach to drawing out the geographic contributions in particular, as well as other key contributions, allows us to identify across Part 1 and Part 2, the broad contours of the climate justice literature of greatest interest to geographers. By presenting an organizational structure to the literature, we hope to expand the climate change justice discussion and to present, at the very least, a compass for future navigation.

Through our synthesis, it becomes clear that distributive justice concerns have taken front seat in the climate justice debates and literature to date. Although a full review of debates within philosophy around social justice is beyond this paper's scope, we do want to point out that these debates are relevant to thinking about and acting for distributive climate justice. A number of climate justice scholars have already engaged with these debates in the context of mitigation and adaptation project benefits (see Part 2). One of the multiple suggested approaches is the utilitarian approach, which suggests that achieving the greatest good for the greatest number of people contributes to fairness in distribution (Paavola and Adger 2006). However, a quite different approach insists that distributive justice should be addressed by assisting the poor and vulnerable first as they have the greatest need and are least likely to be able to cope with climate change on their own (Dow et al. 2010; Kasperson and Kasperson 2001; Ribot 2010). A third approach understands social justice as "spheres of justice," in which equality is obtained by ensuring that groups disadvantaged in one sphere (e.g., income) should not be disadvantaged in other spheres (e.g., health) (Walzer 1983). Further, solutions involving only one sphere (e.g., monetary transfer schemes) do not adequately resolve the uneven and differential effects of climate change as they occur across different spheres (e.g., health, livelihood, land). The capabilities approach (Sen 1985) has also been useful in extending the discussion on distributive justice, raising concerns over the appropriateness of distributed material goods and the actual effect of these distributions on people's overall well-being (Adger et al. 2006; Schlosberg 2007). As these varied and multiple approaches illustrate, solutions to the problem of distributive climate justice are made more complex through competing approaches to social justice.

Our review also confirms that insufficient attention has been paid to questions of procedural climate justice. The existing literature leans heavily on the procedural role of state actors (as we elaborate further in Part 2), with less attention given to other types of actors. Numerous procedural concerns exist: who sits at the table, how they are allowed to participate, whose knowledge counts, and who gets to define the problem. But fundamental to all of these is an underlying question of what are the processes by which the seats are populated. Finney (2009) argues that it matters who gets to extend the invitation to the climate change table: "If I invite you to the table, there are some assumptions that we implicitly agree upon. We go by my rules, my definitions, my frameworks, and often, my goals. These become the filters 
through which we have our dialogue. You become the "added value," but nothing fundamentally changes about the process or the outcomes" (p. 24). Discussions of procedural justice also would benefit from taking into account Fraser's (2005) "all-affected principle." This principle moves us away from focusing on the who and what of justice based on national citizenship (or by extension, United Nations membership). Instead, actors become subjects of justice because of entanglement in a "common structural or institutional framework" (see also review by Barnett 2010). There is a critical need for research that focuses on procedural justice on the local scale. Determining not only what constitutes climate justice claims, but also who makes them and how they do so is imperative if we are to create a democratic process of determining how these claims are to be addressed.

While the justice literature draws clear distinctions between distributive and procedural justice, they are interdependent in the production of just climate outcomes. Those on the short end of distribution likely lack a voice at the procedural level. Moreover, without fairness in process, fairness in distribution is unlikely. Conversely, fair outcomes will lead to greater recognition for the people most affected by climate change, drawing them into the conversation about solutions and thereby increasing overall justice (Adger et al. 2006) and protecting rights of sociocultural difference. The production of just climate outcomes at various scales necessitates a comprehensive theory of justice that takes into account all types of justice. To build such a theory, attention needs to be given to questions including, who gets to make climate justice claims and what power relations allow them to do so; whether or not individuals, groups, and states have access to the political forums necessary to make justice claims; and, how the benefits and harms of climate change are and will be unevenly distributed (see Schlosberg 2007).

In addition, clear attention to the concept of recognition justice is still largely missing in climate justice scholarship. This gap may partly result from the fact that the geographic literature on vulnerability continues to be the main avenue through which questions of social difference are incorporated. This literature has not yet fully intersected with more critical literatures on social and cultural differences, such as critical race theory or feminist theory. Moreover, race seems to constitute a fundamentally missing component in climate justice debates and research. As noted by Roberts (2007), international environmental justice discourse is increasingly moving away from issues of racialized and cultural justice to greater focus on uneven burdens and vulnerabilities in the context of global economic position. To some degree, our review offers empirical evidence of this shift. While vulnerability is certainly an important consideration, it cannot be adequately addressed without understanding how particular socio-spatial patterns such as race shape vulnerability in the first place. Following Pulido (2000), we call for a renewed focus on the racialized drivers of global climate injustices, which draws attention to racialized and hegemonic social processes, structures, and practices that give rise to unjust socio-spatial patterns and discourses. Refocusing on the racialized structural determinants of vulnerabilities and justice outcomes is critical to understanding how specific vulnerabilities and uneven distributions are produced, and how policies can be formulated to address these vulnerabilities. Although it is beyond our scope here, the environmental justice research on racism and Hurricane Katrina provides a window not only into the role played by race in climate justice questions, but also into the sorts of scholarship necessary to illuminate this role (Bullard and Wright 2009; Colten 2006). 
Finally, our synthesis begins to demonstrate the importance of scale in the consideration of climate justice. Here in Part 1, we demonstrate the concept of scale is critical to illuminating the injustices that arise from the uneven effects of climate change. We emphasize the justice implications of scale as an epistemological analytical choice (i.e., unit of analysis). We highlight how broad scale vulnerability assessments tend to homogenize across geographic space and socio-structural position and will likely mask differentiated impacts at the local level. In Part 2 of our review, we will turn to the justice questions around climate action, and in the process, we will further explore the question of scale as material practice and its justice implications. 


\section{Reference List}

Adger, W. (2006). Vulnerability. Global Environmental Change 16(3), pp. 268-281.

Adger, W., Paavola, J. and Huq, S. (2006). Toward justice in adaptation to climate change. In Adger, W., Paavola, J., Huq, S. and Mace, M., (eds.), Fairness in adaptation to climate change. Cambridge: MIT Press, pp. 1-19.

Arora-Jonsson, S. (2011). Virtue and vulnerability: discourses on women, gender and climate change. Global Environmental Change 21, pp. 744-751.

Baer, P., Athanasiou, T., Kartha, S. and Kemp-Benedict, E. (2008). The greenhouse development rights framework: the right to development in a climate constrained world. Berlin: Stockholm Environment Institute.

Barnett, C. (2010). Geography and ethics: justice unbound. Progress in Human Geography 35(2), pp. 246-255.

Blaikie, P., Cannon, T., Davis, I. and Wisner, B. (1994). At risk: natural hazards, people's vulnerability and disasters. London: Routledge.

Bullard, R. Wright, B. (eds.) (2009). Race, place and environmental Justice after Hurricane Katrina. Boulder: Westview Press.

Colten, C. (2006). Vulnerability and place: flat land and uneven risk in New Orleans. American Anthropologist 108(4), pp. 731-734.

Dessai, S., Adger, W., Hulme, M., Turnpenny, J., Kohler, J. and Warren, R. (2004). Defining and experiencing dangerous climate change. Climatic Change 64, pp. 11-25.

Dow, K., Kasperson, R. and Bohn, M. (2006). Exploring the social justice implications of adaptation and vulnerability. In Adger, W., Paavola, J., Huq, S. and Mace, M., (eds.), Fairness in adaptation to climate change. Cambridge: MIT Press, pp. 79-96.

Eakin, H. and Luers, A.L. (2006). Assessing the vulnerability of social-environmental systems. Annual Review of Environment and Resources 31, pp. 365-94.

Eriksen, S., Brown, K. and Kelly, M. (2005). The dynamics of vulnerability: locating coping strategies in Kenya and Tanzania. Geographical Journal 171(4), pp. 287-305.

Farbotko, C. and Lazrus, H. (2012). The first climate refugees? Contesting global narratives of climate change in Tuvalu. Global Environmental Change 22, pp. 382-390.

Finney, C. (2009). What's race got to do with it? Climate change, privilege, and consciousness. Whole Thinking Journal 4(Winter), pp. 21-24.

Fraser, N. (1997). Justice Interruptus: Critical Reflections on the "Postsocialist" Condition. London: Routledge.

Fraser, N. (2005). Reframing justice in a globalizing world. New Left Review 36, pp. 1-19. Handmer, J., Dovers, S. and Downing, T. (1999). Societal vulnerability to climate change and variability. Mitigation and Adaptation Strategies for Global Change 4(3/4), pp. 267 - 281. Heltberg, R., Siegel, P. and Jorgensen, S. (2009). Addressing human vulnerability to climate change: towards a 'no-regrets' approach. Global Environmental Change 19, pp. 89-99. Hulme, M. (2008). The conquering of climate: discourses of fear and their dissolution. Geographical Journal 174, pp. 5-16.

Ikeme, J. (2003). Equity, environmental justice and sustainability: incomplete approaches in climate change politics. Global Environmental Change 13, pp. 195-206.

Kasperson R. and Kasperson, J. (2001). Climate change, vulnerability, and social justice. Stockholm Environment Institute: Stockholm 
Klein, R. and Mohner, A. (2011). The political dimensions of vulnerability: implications for the Green Climate Fund. IDS Bulletin 42(3), pp. 15-22.

Kythreotis, A. (2011). Progress in global climate change politics? Reasserting national state territoriality in a 'post-political' world. Progress in Human Geography, 36(4), 457-474. Leichenko, R.M. and O'Brien, K.L. (2008). Environmental change and globalization: double exposures. Oxford: Oxford University Press.

Liverman, D. (2009). Conventions on climate change: constructions of danger and the dispossession of the atmosphere. Journal of Historical Geography 35(2), pp. 279-296. Marino, E. and Ribot, J. (2012). Adding insult to injury: climate change and the inequities of climate intervention. Global Environmental Change 22(2), pp. 323-328.

McDowell, J. and Hess, J. (2012). Accessing adaptation: Multiple stressors on livelihoods in the Bolivian highlands under a changing climate. Global Environmental Change 22 (2), pp. 342-352. Mearns, R. and Norton, A. (2010). Equity and vulnerability in a warming world: introduction and overview. In Mearns, R. and Norton, A., (eds.), Social dimensions of climate change: equity and vulnerability in a warming world. Washington, DC: The World Bank, pp. 1-44.

O'Brien, K. and Leichenko, R. (2003). Winners and losers in the context of global change. Annals of the Association of American Geographers 93(1), pp. 89-103.

O'Brien, K., Eriksen, S., Nygaard, L.P. and Schjolden, A. (2007). Why different interpretations of vulnerability matter in climate change discourses. Climate Policy 7 (1), pp. 73-88.

Okereke, C. (2006). Global environmental sustainability: intragenerational equity and conceptions of justice in multilateral environmental regimes. Geoforum 37, pp. 725-738. Paavola, J. and Adger, W. (2006). Fair adaptation to climate change. Ecological Economic 56, pp. 594-609.

Peet, R., Robbins, P. and Watts, M. (2011). Global political ecology. New York: Routledge. Pulido, L. (2000). Rethinking environmental racism: white privilege and urban development in southern California. Annals of the Association of American Geographers 90(1), pp. 12-40. Rawls, J. (1971). A theory of justice. Cambridge: Harvard University Press. Ribot, J. (2010). Vulnerability does not fall from the sky: towards multiscale, pro-poor climate policy. In Mearns, R. and Norton, A., (eds.), Social dimensions of climate change: equity and vulnerability in a warming world. Washington, DC: The World Bank, pp. 47-73.

Roberts, J. (2007). Globalizing environmental justice. In Sandler, R. and Pelluzo, P., (eds.), Environmental justice and environmentalism: the social justice challenge to the environmental movement. Cambridge, MA: MIT press, pp. 285-307.

Roberts, J. (2009). The international dimension of climate justice and the need for international adaptation funding. Environmental Justice 2, pp. 185-190.

Roberts, J. and Parks, B. (2009). Ecologically unequal exchange, ecological debt, and climate justice. International Journal of Comparative Sociology 50(3-4), pp. 385-409.

Schlosberg, D. (2007). Defining environmental justice: theories, movements, and nature. New York: Oxford University Press.

Sen, A. (1985). Commodities and capabilities. Oxford: Oxford University Press.

Sturgeon, N. (2007). Environmentalism in popular culture: gender, race, sexuality, and the politics of the natural. Tucson: The University of Arizona Press.

Sultana, F. (2010). Living in hazardous waterscapes: gendered vulnerabilities and experiences of floods and disasters. Environmental Hazards 9(1), pp. 43-53. 
Taylor, T. (2000). The rise of the environmental justice paradigm: injustice framing and the social construction of environmental discourses. American Behavioral Scientist 43(4), pp. 508580.

Terry, G. (2009). No climate justice without gender justice: an overview of the issues. Gender and Development 17(1), pp. 5-18.

Walker, G. (2010). Beyond distribution and proximity: exploring the multiple spatialities of environmental justice. In Holifield, R., Porter, M. and Walker, G., (eds.), Spaces of

environmental justice, United Kingdom: Wiley-Blackwell, pp. 22-46.

Walzer, M. (1983) Spheres of justice: a defense of pluralism and equality. Oxford: Blackwell. 